\title{
Correlation of ErbB2 Gene Status, mRNA and Protein Expression
}

\author{
Maurizio D'Incalci \\ Department of Oncology, Istituto di Ricerche Farmacologiche 'Mario Negri', Milan, Italy
}

The family of ErbB receptors or epidermal growth factor receptors are tyrosine kinases implicated in different human neoplasms [1]. Increased expression and mutation of these receptors have been reported in different carcinomas and in glioblastomas. Amplification of ErbB2 receptor expression, consequent to gene amplification has been demonstrated in a subset of breast cancers corresponding to approximately one third of the patients affected by this disease. The amplification of the gene encoding ErbB2 is not only a biologically relevant feature of some breast tumors, but it is also a useful marker guiding the therapy, i.e. in the subset of patients with ErbB2 gene amplification the chance of response to the therapy with antibodies directed to this receptor (i.e. trastuzumab) is markedly greater than in cases in which the gene is not amplified. Therefore, the overexpression of ErbB2 due to gene amplification represents a useful marker to select breast cancer patients eligible for the therapy with trastuzumab in the current clinical practice.

According to many reports in the recent literature, the overexpression of ErbB2 is not only evident in a fraction of malignant breast tumors, but in many other human tumors including ovarian carcinomas, head and neck cancer, lung and gastro-intestinal tumors [1-8].

These findings are potentially interesting and provide the rationale to investigate if and to what extent trastuzumab, alone or in combination with other drugs, could be used for the therapy of non-breast cancers that overexpress ErbB2. It should be noted that the ErbB2 extracellular region is very different from that of other receptors of the same family. ErbB2 has a conformation that resembles the ligand-activated status and the structural peculiarity of ErbB2 explains why it is the preferred partner of the other activated ErbBs.

Certainly the available data suggest the possibility that clinical investigations should be performed to find out how the overexpression of ErbB2 can be exploited therapeutically.
However, there are many different questions concerning how relevant the expression of this receptor is for the survival, proliferation and metastasis of malignant cells of different origin. This lack of data makes a rational therapeutic approach difficult.

In this issue of ONKOLOGIE, Kuesters et al. [9] show the overexpression of ErbB2 in a variety of human tumors growing as xenografts in nude mice. They have investigated the gene amplification by in situ hybridisation (FISH), quantitated the levels of mRNA and determined the levels of the protein by immunochemistry and ELISA. The integration of all these techniques renders the study of great interest, as it provides information on the mechanism(s) of overexpression occurring in the different human tumors that were analyzed. What is really impressive is the very large number of tumors that were analyzed, more than 100 , and the broad variety of histological types.

A very good correlation was found between mRNA and protein expression levels in the samples. The different levels of expression of ErbB2 allow to divide all tumors in 3 categories, based on the level of expression compared to the average of all samples: those with levels of expression more than 10 -fold higher, those with levels 2-5-fold higher and those with levels close to or below average. Gene amplification is mainly responsible for the very high expression of ErbB2 in the first group of tumors, whereas no gene amplification has been found for the other categories.

The large number of well characterized xenografts described by Kuesters et al. is potentially very useful to characterize how the overexpression of ErbB2 leads to abnormal proliferation, differentiation and survival in different tumor types and is particularly relevant to test preclinical therapeutic strategies directed at ErbB2 also for non-breast carcinomas.

The finding that gastric cancers express very high levels of expression of ErbB2, either with or without ErbB2 gene am-

\begin{tabular}{ll}
\hline KARGER & ( ) 2006 S. Karger GmbH, Freiburg \\
Fax +497614520714 & Accessible online at: \\
$\begin{array}{l}\text { E-mail Information@Karger.de } \\
\text { www.karger.com }\end{array}$ & www.karger.com/onk
\end{tabular}

Prof. Maurizio D'Incalci, M.D.

Department of Oncology

Istituto di Ricerche Farmacologiche 'Mario Negri'

Via Eritrea, 62, 20157 Milan, Italy

Tel. +3902 39014473, Fax +3902 3546277

E-mail dincalci@marionegri.it 
plification and that adenocarcinomas of the lung overexpress the receptor suggest that trastuzumab or other ErbB2-directed therapies should be evaluated in these neoplasms at clinical level. Preclinical testing should be performed in order to evaluate how to investigate these therapies in the clinic in the most rational way and how to select the patients who will have the highest chance of response. The characterization of the expression of ErbB2 shown in the paper by Kuesters et al. makes it now feasible to undertake this preclinical investigation in the most effective way. Furthermore these animal models provide unique tools to investigate the molecular mechanisms that are crucial for the response to anti-ErbB2 therapies and to investigate different combinations. In this regard it seems attractive not only to investigate combinations involving the drugs currently used in the clinic for these malignancies, but also to attempt to create synergies by the concomitant use of anti-ErbB2 antibodies and other inhibitors of signal transduction pathways. This approach is theoretically sound and the oncologists urgently need these data.

\section{References}

1 Hynes NE, Lane HA: ERBB receptors and cancer the complexity of targeted inhibitors. Nat Rev Cancer 2005;5(5):341-354.

2 Weed DT, Gomez-Fernandez C, Pacheco J, Ruiz J, Hamilton-Nelson K, Arnold DJ, Civantos FJ, Zhang J, Yasin M, Goodwin WJ, Carraway KL: MUC4 and ERBB2 expression in major and minor salivary gland mucoepidermoid carcinoma. Head Neck 2004;26(4):353-364.

$\checkmark 3$ Cohen EE, Lingen MW, Martin LE, Harris PL, Brannigan BW, Haserlat SM, Okimoto RA, Sgroi DC, Dahiya S, Muir B, Clark JR, Rocco JW, Vokes EE, Haber DA, Bell DW: Response of some head and neck cancers to epidermal growth factor receptor tyrosine kinase inhibitors may be linked to mutation of ERBB2 rather than EGFR. Clin Cancer Res 2005;11(22):8105-8108.
- 4 Yu X, Guo ZS, Marcu MG, Neckers L, Nguyen DM, Chen GA, Schrump DS: Modulation of p53, ErbB1, ErbB2, and Raf-1 expression in lung cancer cells by depsipeptide FR901228. J Natl Cancer Inst 2002;94(7):504-513

5 Senior K: ERBB2 kinase mutations in lung-cancer tumours. Lancet Oncol 2004;5(11):647.

6 Altimari A, Fiorentino M, Gabusi E, Gruppioni E, Corti B, D'Errico A, Grigioni WF: Investigation of ErbB1 and ErbB2 expression for therapeutic targeting in primary liver tumours. Dig Liver Dis 2003; 35(5):332-338.

7 Sato T, Konishi K, Maeda K, Yabushita K, Miwa A: Integrin alpha v, c-erbB2 and DNA ploidy in lung metastases from colorectal cancer. Hepatogastroenterology 2003;50(49):27-30.
8 Lee JW, Soung YH, Kim SY, Park WS, Nam SW, Kim SH, Lee JY, Yoo NJ, Lee SH: ERBB2 kinase domain mutation in a gastric cancer metastasis. Apmis 2005;113(10):683-687.

$\checkmark 9$ Kuesters S, Maurer M, Burger AM, Metz T, Fiebig $\mathrm{HH}$ : Correlation of ErbB2 gene status, mRNA and protein expression in a panel of $>100$ human tumor xenografts of different origin. Onkologie 2006;29: 249-256. 